\title{
Evolution of the Thyroid Hormones and Thyreostimulin in Obese Children
}

\author{
LAVINIA OCHIANA ${ }^{1}$, EMILIANA TEODORA DRAGO MIR ANANIE2 ${ }^{2}$ IOANA ANCA BADARAU ${ }^{3}$ SERBAN PAPACOCEA4, \\ MIHNEA COSTIN MANEA ${ }^{5}$, RAZVAN PAPACOCEA ${ }^{4}$, MIRELA MANEA ${ }^{5}$, ANA CLAUDIA DAMİAN ${ }^{6}$, IOANA RALUCA PAPACOCEA ${ }^{3 *}$, \\ ADELA MAGDALENA CIOBANU6 \\ IUniversity Dunarea de J os Galati, 47 Domneasca Str, 800008, Galati, Romania \\ ZUniversity of Pharmacy and Medicine Craiova, 2 Petru Rares Str., 200349, Craiova, Romania \\ ${ }^{3}$ Carol Davila University of Medicine and Pharmacy, Faculty of Medicine, Discipline of Physiology I, 8 Eroi Sanitari Blvd, 050474, \\ Bucharest, Romania \\ ${ }^{4}$ Carol Davila University of Medicine and Pharmacy, Faculty of Medicine, 8 Blvd Eroilor Sanitari, 050474, Bucharest, Romania \\ ${ }^{5}$ Carol Davila University of Medicine and Pharmacy, Faculty of Dental Medicine, Discipline of Psychiatry and Psychology, Prof. $d r$. \\ Al. Obregia Clinical Hospital, 10 Berceni Str. 041914, Bucharest, Romania \\ ${ }^{6}$ Carol Davila University of Medicine and Pharmacy, Faculty of Medicine, Discipline of Psychiatry, Prof dr. Al. Obregia Clinical \\ Hospital, 10 Berceni Str. 041914, Bucharest, Romania
}

\begin{abstract}
The study objective is the correlation of thyroid function to the weight status in a study group made up of schoolchildren in Galati County. Six of ten overweight children before puberty will became obese during adulthood. PREDATORR study published in May 2014, placed our country in the top among overweight and obesity European incidence, showing a 34.7\% prevalence of overweight and $31.9 \%$ obesity in subjects in the age group 20-79 years. Unfortunately the study did not offer epidemiological data regarding children population. The data obtained allow the characterization of the thyroid function in relation to weight status in school age children, in a county both in urban and rural area, taking in account that there are fewer studies in rural in this moment. It brings further information on thyroid function and pathology in pediatric obesity in relation to metabolic comorbidities. We identified an increased fT3 and TSH in obese children, sustaining the association between dyslipidemia, thyroid function, anxiety and depression, as long as the data obtained adult are still controversial.
\end{abstract}

Keywords: children, obesity, thyroid function, anxiety, depression

In the pastyears, due to the significantincrease of numbers of obese or overweightchildren and adolescents, World Health Organization declared that obesity became pandemic. [1-3]. The major behavioral factors that increase the risk of obesity are lifestyle and hyper-caloric diet In the lastdecades, due to the changes in lifestyle, childhood obesity has become epidemic. The childhood obesity prevalence is also growing rapidly in Romania, PREDATORR study published in May 2014, the largest population-based study on overweight, and metabolic comorbidities in diabetic nephropathy in Romania, places our country in the top among overweight and obesity European ranks, showing a 34.7\% prevalence of overweight and $31.9 \%$ obesity in subjects in the age group 20-79 years. Unfortunately did not offer data for children population. However, a local survey showed that the prevalence and severity of obesity and overweightamong Romanian children has an ascending trend because of the low level of physical activity and the inappropriate life-style [4] .

Being multi factorial and complex disease obesityis related with behavioral, endocrine and metabolic changes, leading to multi-system malfunctions. In this sense are well defined the obesity-related implications on endocrine system, nervous and cardiovascular function $[5,6]$.

The key role in these implications is a chronic low grade inflammation, which has impact on brain function and structure, translated into cognitive, mood and emotional changes $[7,8]$.

Excessive food intake doubled by a poor quality food, translated into a high content of fats and sugars are associated with an increased incidence prevalence of anxiety disorders not only in adults, but also in children [9].
Depression and anxiety in children are positively associated with obesity and these relation present an increasing evolution in last decades [10]. Obesity induces various thyroid functions abnormalities to elevated TSH and/ or fT3 levels. Several studies are showing high TSH concentration in subjects with BMI over $30 \mathrm{~kg} / \mathrm{m}^{2}$ [11]. Subclinical hypothyroidism (with fT3 and fT4 concentrations in range but increased concentration of TSH) is often met in adults butrecently observed in a high number of children and young adults with the same abnormalities. The primary endpoint of the study is the evaluation of the thyroid function in correlation to epidemiological characterization of the weight status of a study group made up of schoolchildren in Galati County; we also tracked the association with anxiety and depression.

Previous papers showed that hypothyroidism induced by imbalances in food intake, will lead to increase fat deposits and in the end could end up in thyroid obesity. Recent reports showed that thyroid dysfunction could be caused by obesity alone; more, body fat percentage changes and thyroid activity in obese children can be used as clinical features of this concept. Several trials showed the clear link between BMI and the thyroid function. Also, increased adiposity can lead to thyroid structure changes; after weight loss, thyroid hormone level usually normalizes. In these data, the chronicity of the thyroid imbalance in adulthood had not been proved [12].

There are scientists that consider that most of the children with such imbalances are unnecessarily treated with thyroid hormones, only because of a mild elevation of 
the TSH level [13-15]. Some of the first reports of mildly elevated TSH in obese children were initially published in Germany [15] and were followed by other smaller trials across the Europe which confirmed high prevalence of elevated serum TSH, T4 and T3 in obese children [16].

\section{Experimental part}

Our study is a longitudinal study of national representative cohort ( 4147 subject $-1,766$ boys and 2,381 girls). Individuals over 10 years old (born between 1998 and 2006) were taken in consideration for obesity and metabolic syndrome. The height, weight and physical activity level was evaluated among children from different schools all-around Galati County from both urban and rural environment. The data were gathered by auxology trained physical therapists and medical students. Table 1 presents the study populations, data sources, and sample sizes.

From this initial sample of subjects were selected randomly 50 normal weight subjects (control group) and 100 subjects identified as overweight and obese (obese, active group). After the signing of the Inform Assent from the child and Informed Consent from the parents, demographic data, disease history (for parents and child) including obesity incidence in the family history, lifestyle, dietary habits, physical activity level, socio-economic condition and the age when the increase of weight was observed were collected for each subject.

For all subjects selected have been prepared consultation sheets, in which were recorded nonspecific determinations, glycaemia level, total cholesterol and fractions high density lipoprotein, thyroid ultrasound and specific dosage of Thyroid Stimulating Hormone (TSH), thyroxine (T4), triiodothyronine (T3), free-T4 (fT4), free -T3 (fT3), Anti-thyroid peroxidase antibodies (Anti-TPO), antithyroglobulin antibodies (Anti-Tg) and iodide. The subjects were classified as obese if their BMI was $>97$ th percentile, using as guidance of the International Task Force of Obesity in Childhood and Population-specific Data.3

The patient's fT3, fT4 and TSH concentrations were evaluated with direct chemiluminescence (ADVIA Centaur XP, USA). Normal ranges were $0.8-5.4 \mathrm{ulU} / \mathrm{mL}$ for TSH, 4.3-8 pmol/L for fT3 respectively b etween $10.3-25.7$ $\mathrm{pmol} / \mathrm{L}$ for fT4. The levels of anti-Tg and anti-TPO were evaluated with chemiluminescence competitive immune test ADVIA Centaur, (USA) in case that the patients had TSH concentration over the limit of $5.4 \mathrm{IU} / \mathrm{mL}$. Subjects with concentration of anti-TPO (0-35 IU/mL) and anti-Tg $(0-115 \mathrm{IU} / \mathrm{mL})$ higher than the reference ranges had to be tested for autoimmune thyroid disease. The thyroid echography was performed to evaluate the heterogeneity of the thyroid mass and to measure the thyroid volume.

The active group was for 3 months under a hypocaloric diet and coordinated physical therapy protocol created by Alexe 0 et al. [17]. At the end of the 3 months period all determinations were repeated for the subjects with significant weight loss $-3 \mathrm{Kg}$ or more.

Data were analysed both cross-sectional and longitudinally using the SPSS 2009 (statistical package Version 14, SPSS Inc., Chicago, IL), with user-defined commands. The T-TEST was used to evaluate the differences of the two parameters in groups; The Tukey multiple comparison was also used to analyse the difference of parameters and T TEST was used see any differences between the two different groups. The chisquare test, $p<0.05$ was accepted as statistically significant for the data gathered.

\section{Results and discussions}

As seen below the distribution of gender and age were not statistically different between the two (groups control and obese) - $p=0.729$. The average age of the subjects was $10.5 \pm 2.6$ years in the control group and $10.8 \pm 3.9$ years in the active group. The mean body mass index was $27.5 \pm 4.1$ in the active group, there was statistically significant difference between the two groups for the body mass index 17.6 \pm 2.7 ( $p=0.0001$ ) (Table 1).

After the evaluation of the fT3 levels were significantly higher in active group than the control group $(p=0.002)$, although the concentrations of fT 4 compared amongst the two groups $(p=0.807)$ showed no statistically significant difference - Table 2. When the mean TSH levels were analysed and compared between the two groups the data showed that the active group had higher TSH levels compared with the control group $(p=0.001)$ indicating that the chance of having subclinical hypothyroidism in active group was 2.45 times higher than in the control group Table 3.

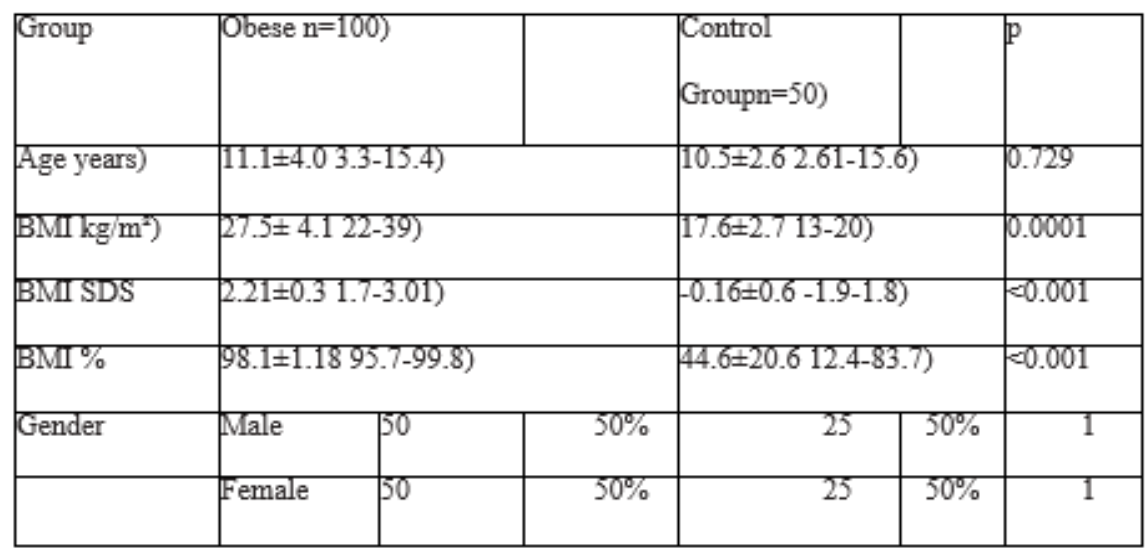

\begin{tabular}{|c|c|c|c|}
\hline & Obese $\mathrm{n}=100)$ & Control group n=50) & $\mathrm{p}$ \\
\hline $\left.\mathrm{fT}_{3} \mathrm{pmol} / \mathrm{L}\right)$ & $5.9 \pm 1.13 .04-8.6)$ & $(5.4 \pm 0.94 .1-6.7)$ & 0.002 \\
& & & 0.807 \\
\hline $\mathrm{fT}_{4 \mathrm{pmol} / \mathrm{L})}$ & $16.8 \pm 2.0111 .8-22.6)$ & $(16.9 \pm 2.414 .1-24)$ & \\
\hline $\mathrm{TSH} \mathrm{UI} / \mathrm{ml})$ & $3.9 \pm 1.41 .3-7.7)$ & $(3.2 \pm 1.11 .2-6.1)$ & 0.001 \\
& & & \\
\hline
\end{tabular}

Table 1

THE DEMOGRAPHICAL DATA, BODY MASS INDEX MEAN) OF OBESE AND CONTROL GROUPS [MEAN \pm STANDARD DEVIATION RANGE)]

Table 2

THYROID HORMONE CONCENTRATIONS IN OBESE AND NO CONTROL GROUP (MEAN STANDARD DEVIATION RANGE) 


\begin{tabular}{|l|c|c|c|c|}
\hline & Active group n \%) & Control group n \%) & Difference & \\
\hline TSH level $\geq 5.4$ & $(6262)$ & $(4080)$ & $\square^{2}: 4,84$ & 2.45 \\
\hline $\begin{array}{l}\text { TSH level }>5.4 \\
\text { with high anti- }\end{array}$ & $(3838)$ & $(1020)$ & $\mathrm{p}=0,028$ & $1.1-5.9$ \\
TPO \& anti-Tg & & & & \\
levels & & & & \\
\hline
\end{tabular}

Table 3

THE RISK OF DEVELOPING

SUBCLINICAL HYPOTHYROIDISM IN BOTH GROUPS
TSH levels above 5.4 combined with increased anti-TPO and anti-Tg levels were observed in just one case of the 38 patients.

Those patients with increased TSH levels underwent thyroid ultrasound examination. The volume of the thyroid was found as in within normal ranges in each case. In three situations were found to have some signs of thyroiditis without thyroid enlargement.

Energy balance and adiposity are in direct feedback with thyroid hormones. Data published from trials with the primary endpoint to find the correlations between thyroid hormones and obesity showed that, TSH, fT 3 and fT 4 values shows the discrepancies in obese subjects. $[18,19,20]$

In the present trial, TSH and fT3 concentrations were high in obese and overweight children compared with normal weight children event though the fT4 concentrations were similar amongst the two groups. Stichel et al. published similar results have been shown [15] as T4 concentrations were the same, while the TSH and T3 levels were found within normal ranges, even if were found significantly higher in the obese group than in the control group [21]. Reinehr et.al measured the effects of weight loss on thyroid activity amongst obese children and concluded that fT3 and TSH concentrations were slightly high amongst obese children and that the loss of body mass had the effect of reduction in the levels of these hormones. This decrease supports the hypothesis that the high levels of fT3 and TSH are a consequence and not a cause of obesity. This type of subclinical hypothyroidism characterized by moderate increase in TSH and fT3 levels could be explained in relationship with the thyroid hormones resistance in peripheral tissues and lower negative feedback between TSH and the peripheral thyroid hormones [22]. In such cases the incidence of anxiety and depression is increased; these cognitive disturbances may also appear in other brain pathologies such as cerebral tumours, frequently in meningiomas [7, 23].

Bhowmick et al. reported a high concentration of TSH among obese subjects combined with positive thyroid peroxidase and anti-thyroglobulin confirming the correlation between body mass index and thyroid function [24]. Also, high concentrations of TSH were found to be correlated with positive thyroid peroxidase and thyroglobulin antibodies as a response of a thyroid dysfunction.

Some trials confirmed the high concentration of antibodies in obese subjects and these data have been correlated with thyroiditis, supporting a role for the inflammatory mechanisms and bringing in discussion a possible role for anti-inflammatory therapies $[25,26]$.

This thyroiditis was although related with the increased concentrations of antigen present in the glandular parenchyma caused, maybe, by the iodine uptake as the thyroid dimensions were within normal ranges $[27,28]$. The presence of these antibodies may also be related to metabolic syndrome, nonalchoholic fatty liver disease [29] and liver fibrosis which can be assessed noninvasively [30,
31] especiallyin children. In addition the negative feedback between TSH and the peripheral concentration of thyroid hormones could be dysfunctional in obese subjects explaining the high levels of TSH and peripheral thyroid hormones in obesity. However, the degree of depression associated to these changes should be further investigated as long as other pathologies characterized also by brain inflammation may produce anxiety and depression [31, 32].

\section{Conclusions}

Concluding, the present paper confirms findings from the past that obesity is in directrelationship with a moderate increase in TSH and fT3 levels, but rather as an adaptive process, and has no correlation with autoimmune thyroiditis or hypothyroidism in children. These subjects are not to be advised to undergo any thyroid hormone replacement therapy for mild increase of TSH concentration elevation instead it would be advisable to follow personalized dietary and exercise programs aiming the normalization of the glandular functions. The final results of our trial will confirm or infirm the effectiveness of dietary and physical therapy intervention on the selected subjects.

\section{References}

1. TAHERI, F., CHAHKANDI, T., KAZEMI, T., NAMAKIN, K., ZARDAST, M., BIJ ARI, B. Int J Prev Med, 5 no.9, 2014, p. 1198.

2. DAVISON, K. K., BIRCH, L. L. Obes Rev 2, no.3, 2001, p.159.

3. Fu, W. P. C., Lee, H. C., Ng, C. J., Tay, Y. D., Kau, C. Y., Seow, C. J., Hong, C. Y. Int J Obesity, 27, no.9, 2003, p. 1121.

4. ALEXE OS, NEAMTU C, IFTENI.G. Diabetes, Obes Metab, 12, 2010. 5. IBANEZ, L., VALLS, C., FERRER, A., MARCOS, M. V., RODRIGUEZHIERRO, F., DE ZEGHER, F. J Clin Endocrin Metab 2001; 86, no.8, 2001, p. 3595 .

6. POPESCU, L. A., VIRGOLICI, B., STEFAN, D. C. A., LIXANDRU, D., TIMNEA, O., VIRGOLICl, H., MOHORA, M. Rev. Chim. (Bucharest), 68, no.4, 2017, p. 758.

7. ADELANTADO-RENAU, M., ESTEBAN-CORNEJ O, I., RODRIGUEZAYLLON, M., CADENAS-SANCHEZ, C., GIL-COSANO, J. J., MORAGONZALEZ, J., VERDEJ O-GARCIA, A. Brain, behav immun. 2019, https:/ /doi.org/10.1016/j.bbi.2019.07.020

8. EPINGEAC, M. E., GAMAN, M. A., DIACONU, C. C., GAD, M., GAMAN, A. M. Rev. Chim. (Bucharest), 70, no.6, 2019, p.2241.

8. KOHLBOECK, G., SAUSENTHALER, S., STANDL, M., KOLETZKO, S., BAUER, C. P., VON BERG, A., HERBARTH, O. Ann Nutr Metab, 60, no. 4, 2012, p.247.

9. QUEK, Y. H., TAM, W. W., ZHANG, M. W., HO, R. C. Obes rev, 18, no.7, 2017, p.742.

10. MUTLU, R. G. Y., OZSU, E., CIZMECIOGLU, F. M., HATUN, S. Turk Arc Ped, 46, 2011, p.33.

11.BASTEMIR M, AKIN F, ALKIS E, KAPTANOGLU B. Swiss Med Wkly, 137, p.431.

12.GLASS AR, KUSHNER J. Endocrinologist, 6, 1996, p.392.

13.KOPELMAN PG. Bailere's Clin Endocrinol Metab, 8, 1994, p.549.

14. STICHEL H. ALLEMAND D, GRUTER A. Horm Res, 54, 2000, p.14.

15. REINHER T, ANDLER W. Arch Dis Child, 87, 2002, p.320. 
16. ALEXE, O., ION-ENE, M., NEAMTU, C., MOROSANU, M. Obesity Facts, 2, 2009

17. RAJALA MW, SCHERER PE. Endocrinology, 144, no.9, 2003, p. 3765.

18. RONDINONE CM. Endocrine 2006; 29, no.1, 2006, p.81.

19. SORISKY A, BELL A, GAGNON A. Horm Metab Res, 32, no.11/12, 2000, p.468.

20. BELL A, GAGNON A, GRUNDER L, PARIKH SJ, SMITH TJ , SORISKY, Am J Physiol Cell Physiol, 279, no.2, 2000, p. 335.

21. REINEHR T, ANDLER W. J Clin Endoc Metab, 91, no.8, 2006, p. 3088.

22. PAPACOCEA, T., ROSCA, T., BADARAU, A., PAPACOCEA, R., CIORNEI, C., ION, A. D. Chirurgia, 104, no.1, 2009, p.99.

23. BHOWMICK SK, DASARI G, LEVENS KL, RETTIG KR. J Natl Med Assoc 2007; 99, no.7, 2007, p.773.

24. VERSINI, M., JEANDEL, P. Y., ROSENTHAL, E., SHOENFELD, Y. Mosaic of Autoimmunity, Academic Press, 2019, p. 343.
25. OLARIU, L., DUMITRIU, B., CRACIUN, L., BUSE, E., ROSOIU, N., BOJ INCA, M., PAPACOCEA, T. Farmacia, 66, no.3, 2018, p. 524.

26. KNUDSEN, N., LAURBERG, P., RASMUSSEN, L. B., BULOW, I., PERRILD, H., OVESEN, L., J ORGENSEN, T. J Clin Endocrin Metab 2005; 90, no.7, p.4019.

27. LIMA N, CAVALIERE H, MEDEIROS-NETO G. Med Sci Res 1987; 15, p. 31.

28. CHEN, Y., WANG, N., CHEN, Y., LI, Q., HAN, B., CHEN, C., LU, Y. Autoimmun, 51, no.5, 2018, p.238.

29. FIERBINTEANU-BRATICEVICI, C., PAPACOCEA, R., TRIBUS, L., CRISTIAN, B. Ind J Med Res, 140, no.1, 2014, p.123.

30. BLACHNIO, A., PRZEPIORKA, A., GORBANIUK, O., BENVENUTI, M., CIOBANU, A. M., SENOL-DURAK, E., POPA, C. Cultural Correlates of Internet Addiction. Cyberpsychol Behav SocNetw, 22,no.4, 2019, p. 258.

31. TOTAN, M., ANTONESCU, E., CATANA, M. G., MITARIU, M. M. C., DUICA, L., FILIP, C. R., MITARIU, S. I. C. Rev. Chim. (Bucharest), 70, no.6, 2019, p. 2290.

Manuscript received: 13.06 .2019 